\section{Sleep and Bedtime Beverage}

SIR,-Investigations from London (20 May, p. 429) and from Edinburgh (p. 431) on the merits of a popular bedtime beverage are reported. The London workers have concluded that Horlicks in milk reduced the number of small movements made by their four subjects during sleep. The Edinburgh workers concluded that sleep after Horlicks was more restful (18 subjects).

It seems to us that the experimental approach in both studies could and should be criticized. The authors do not appear to have adverted to the bearing of subjective influences on the quality of sleep. The investigators and their subjects were aware of the distinction between the trial and the control beverages. In the Lundon group hot water or no drink was used as a control. An inert capsule was used in Edinburgh. This means that each subject knew whether or not he had taken Horlicks on a particular night. Horlicks might well have induced a more restful sleep under these circumstances regardless of its intrinsic merits. It should not have been too difficult to prepare a control drink indistinguishable from Horlicks in flavour and colour (for example, by taking the drinks in darkness, and by adding vanilla essence to the Horlicks and to a control beverage). Milk alone could well have been used as a first step in the investigation. Plain milk was rejected "because if no difference were found between it and the Horlicks drink we should not know whether both had been without action on sleep or whether each had had a positive but similar effect." Isn't this a sophism?

We note that one of the investigators had an attitude of "slightly amused scepticism." In view of the evidence presented, this attitude seems to us to be justified.-We are, etc.,

JEAN C. Folan

TIMOTHY M. O'BRIEN Medical Students

Department of Anatomy,

University Co.lege,

SIR,-Assuming the roles of both the professional statistician and interested bystander, I feel that recent articles on the effects of Horlicks on sleep (20 May, p. 429 and 431) warrant some comment.

I find the choices of control in both trials insufficient. Is it the Horlicks or the ho milk producing the effect on sleep? The premise of Drs. V. Błezinová and I. Oswald that they "rejected plain milk because if no difference were found between it and the Horlicks drink we should not know whether both had been without action on sleep or whether each had had a positive but similar effect" brings ridicule to the concept of the controlled clinical trial. The eventuality of a detectable difference is swept aside by their hypothesis. Surely, in addition to placebo and no treatment, a worthwhile trial mus include both hot milk alone and Horlicks made with hot water (one of the recommendations of the manufacturers) as two control treatments?

Only on the basis of such investigations can one feel justified in advocating the truly benefic:al beverage to the restless nocturnal sufferer.-I am, etc.,

Aviva Petrie Department of Medical Statistics and Epidemiology,
London School of Hygiene and Tropical Medicine, London W.C.1
SIR,-While in their papers on bedtime beverages and sleep (20 May, pp. 429 and 431) Dr. P. R. Southwell and others, and Drs. Vlasta Brézinova and Ian Oswald give evidence that the hypnotic effect of bedtime milk beverages enriched with Horlicks is really attributable to the latter, they ignore that tryptophan (which is abundant in milk protein) has been shown ${ }^{1}$ to significantly increase sleep time, reduce sleep latency, and the number of awakenings.

Moreover Hartmann, Chung, and Chien ${ }^{1}$ explicitly quote that milk beverages at bedtime are accredited with a hypnotic effect.

This reduces much the worth of these two papers.-I am, etc.,

Instituto di Farmacologia,
Università di Camerino, Ital

LUCIANO ANGELUCCI

Hartmann, E., Chung. R., and Chien, C.-P., Psychopharmacologia, i971, 19, 114,

\section{Treatment of Early Breast Cancer}

SIR,-We read with great interest the long awaited results of the Guy's trial on the treatment of early breast cancer by Sir Hedley Atkins and others (20 May, p. 423). Lest the casual observer be persuaded to conclude that radical mastectomy with radiotherapy is the best treatment available for patients in stage II, we would like to make these comments.

Firstly, we suggest that radiotherapy is being used with the same intent as surgical excision of the axillary nodes-to treat tumour cells in a regional field beyond the limits of the primary growth. Thus, both the treatment regimens, radical mastectomy with radiotherapy and extended tylectomy with radiotherapy, are radical in concept. Based on traditional views of the gradual spread of the disease from the breast to lymph nodes and beyond, the aim in either case is to treat the maximum amount of tissue possible. Such principles, as Sir Hedley Atkins and his colleagues admit, are seriously questioned today.

Secondly, the results of previous controlled trials ${ }^{12}$ have suggested that the addition of radiotherapy to radical mastectomy is not only unnecessary but potentially harmful. Furthermore, the Cambridge study ${ }^{3}$ demonstrated that in terms of survival and local recurrence simple mastectomy with radiotherapy was equal to radical mastectomy with radiotherapy, and in terms of morbidity was superior. It would indeed be a retrograde step if evidence from these studies were ignored.

Thirdly, it may not be justified to excise clinically involved axillary nodes. In the $25 \%$ or so which are the seat of reactive changes, excision and/or irradiation may be positively harmful. In those nodes which contain tumour irradiation may well destroy local immunity. The higher local and distant recurrence rates and ten year mortality rates in the stage II tylectomy group could be thus explained.

We feel that the question of whether to treat involved or uninvolved regional nodes has not been answered by this trial, and anticipate that a clearer lead will be given by another trial in which a radical regimen is being compared with a regimen that is truly conservative. ${ }^{4}$

We entirely agree with the authors suggestion that there is no one treatment that should be applied exclusively to all cases of breast cancer at the stage of the disease when radical mastectomy is a practical proposition. We would hope that the paper would not lead clinicians to the conclusion that a radical mastectomy with radiotherapy is today's "best buy."-We are, etc.,

Diana BRINKLEY MichaEl BAum MICHAEL EDWARDS

King's College Hospital Medical School,

London S.E.S

1 Patterson, R., and Russell, M. H., fournal of the Faculty of Radiologists, 1959, 10, 175 . Fisher, B., in Surgery Annual, 3rd ed. P. Cooper and L. M. Nyhus, p. 227. New York, Appleton, 1971

3 Brinkley, Diana, and Haybittle, J. L., Lancet, 1966, 2, 291.
Lancet, 1969, 1175.

\section{Value of Mammary Thermography}

SIR,-The article on the "Value of Mammary Thermography in Differential Diagnosis" (6 May, p. 316) provides exemplary proof that the right technique used in the wrong way equals failure, or as the mathematicians put it-anything multiplied by zero is still zero.

In the first place thermography is not now, nor has it ever been a diagnostic technique. In the study of female breasts it is simply a technique which, imposing no burden on the woman, provides a means for the separation of the population studied into high and low risk groups. If I read the results of Dr. B. E. Nathan and others correctly they were able, from a preselected population, correctly to place $79 \%$ of those with cancer in the high risk group while they divided the remaining cases almost equally between the two groups. An indication of the clinical suspicion rate might well be judged from the biopsy rate which was about 36\%.

Perhaps a more meaningful investigation, in a clinical sense, would be one which sought to answer the question whether the addition of thermography to the clinical examination can assist in altering the survival rate of women who have breast cancer. We probably should leave the diagnosis to the histologist and not depend on thermography, mammography, the sense of touch, or gross visual examination, alone or in combination, to fulfil this clinical need.-I am, etc.,

Department of Radiology,

Jefferson Medical College, Thomas Jefferson University

John D. Wallace

\section{Bicentenary of Nitrous Oxide}

SIR,-In the leading article Bicentenary of Nitrous Oxide (13 May, p. 367), scant tribute is paid to Horace Wells, for in spite of the apparent failure of his demonstration at the Massachusetts General Hospital, it was a fact that many dentists started to use nitrous oxide in their practice. This is corroborated by a paragraph which appeared in the Boston Medical and Surgical fournal (now the New England Fournal of Medicine) on 18 June, 1845: "the nitrous oxide gas has been used in quite a number of cases by our dentists during the extraction of teeth and has been found by its excitement, perfectly to destroy pain. The patient appears very merry during the 